\title{
Molecular Marker Linkage Map ror Apple
}

MA. Hemmat, N. F. Heeden, A. G. Mlanganaris, and D. M. Lawson

\begin{abstract}
Linkage maps for two apple clones, White Angel and Rome Beauty, were constructed using isozyme and DNA polymorphisms segregating in a population produced from a Rome Beauty $\times$ White Angel cross. The linkage map for White Angel consists of 253 markers arranged in 24 linkage groups and extends over 950 ciA. The Rome Beauty map contains 156 markers on 21 linkage groups. The White Angel map was taken as the standard, and we were able to identify linkage groups in Rome Beauty homologous to 13 White Angel linkage groups. The location of several genes not segregating in the Rome Beauty $\times$ White Angel population could be determined on the basis of known linkages with segregating markers. Hence, the standard map for apple now contains about 360 markers, with most linkage groups saturated at 10$15 \mathrm{cM}$. The double pseudotestcross format of the mapping population permitted the comparison of recombination frequencies in male and female parents in certain regions of the genome where appropriate markers were available. The recombination frequencies observed for the approximately $170 \mathrm{cM}$ that were comparable gave no indication that a sex-related difference in recombination rate was characteristic of apple.
\end{abstract}

The domesticated apple (Malus $\times$ domestica Borkh.) is not commonly used in molecular genetic studies. The long generation time, large plant size, high chromosome number $(2 n=34)$, and self incompatibility typical of this species have made apple, as well as many other woody perennials, less appealing to geneticists than species such as maize tomato, and Arabidopsis thaliana. Yet linkage maps and molecular tags for characters expressed late in development would be particularly useful in breeding programs for long-lived perennial crops. Early screening for fruit quality traits, precocity, or growth habit would permit much more efficient use of available orchard space, and marker-based cloning of specific genes would greatly enhance our ability to make minor changes in popular varieties.

Many woody species exhibit high levels of genetic polymorphism (Hamrick and Godt 1990), and in outcrossing species this high polymorphism usually produces a high level of heterozygosity in individual plants. Thus, many loci will be segregating in the gametic population from a single plant, and if these gametes can be examined individually a linkage map can be easily generated. Conifers such as pines and firs produce a relatively large megaga- metophyte. This haploid tissue has provided an excellent tool for genetic investigations of isozyme loci (Cheliak et al. 1984; Eckert et al. 1981; El-Kassaby et al. 1982; Guries et al. 1978; O'Malley et al. 1979), restriction fragment length polymorphisms (RFLPs) (Neale and Williams 1991), and random amplified polymorphic DNA (RAPDs) (Carlson et al. 1991). Linkage maps have been constructed for single trees of loblolly pine (Grattapaglia et al. 1992) and white spruce (Tulsieram et al. 1992) by a thorough study of the loci segregating in the megagametophytes.

Angiosperms rarely produce gametophytes that are large enough to provide sufficient tissue for multilocus studies. Instead, backcross, testcross, or $F_{2}$ populations generally have been selected to examine the segregation of gametes from a heterozygous individual. Commonly, the heterozygous individual is generated as a hybrid between two relatively homozygous lines. However, in apples and many other outcrossing species, this initial step is unnecessary. Each apple variety is highly heterozygous due to the clonal nature of the crop and the poor performance associated with inbred material. Inbreeding depression also precludes the regular use 
of backcross or testcross populations for genetic analysis because inbred lines are not available. Instead, a pseudotestcross design is typically used in which the variety of interest is crossed to a standard variety known not to segregate for the traits being investigated. The segregation ratio for single gene traits is $1: 1$ in such a population, and genetic analyses can be relatively simple.

A refinement of this approach is to perform genetic analysis on both parents in a controlled cross by keeping track of which loci are heterozygous in each parent. Such a "double pseudotestcross" format represents the basic experimental design in most apple breeding programs and has been used to identify linkage relationships among isozyme loci and between isozyme loci and other traits of practical interest to breeders (Chevreau and Laurens 1987; Manganaris and Alston 1987, 1988a,b; Weeden and Lamb 1987). In the research reported here we expanded the type of markers used in apple to include both DNA restriction fragment length polymorphisms (RFLPs) and random amplified polymorphic DNA (RAPDs) in order to generate a relatively saturated genetic map for each parent. We then attempted to combine the two maps into a more general linkage map for the species.

\section{Materials and Mlethods}

\section{Plant Material}

We used data collected from 56 trees produced from a Rome Beauty $\times$ White Angel cross to construct the linkage map. The cross had been made in 1986 by R. C. Lamb, Department of Horticultural Sciences, Cornell University. The seeds were germinated the following year after treatment at $5^{\circ} \mathrm{C}$ for 90 days to break dormancy. Survival of seedlings was excellent, so that the progeny represented a relatively unbiased sample of the original seed population. Rome Beauty is a commonly cultivated apple originally found in a fence row in Ohio in 1848 (Beach et al. 1905). White Angel is a crabapple of unknown parentage discovered in Inglis nursery about 1947 (Jefferson 1970). Analysis of its $45 S$ ribosomal DNA restriction pattern suggests that it has Malus seiboldii in its ancestry (Simon and Weeden 1991). White Angel is believed to be heterozygous for a dominant gene conferring resistance to powdery mildew (Podosphaera leucotricha) (Manganaris and Alston 1992), whereas Rome Beauty is highly susceptible.

\section{Isozyme Systems}

Except where noted, we performed isozyme analysis on young leaves collected in the spring. Analyses of polymorphism for aspartate aminotransferase (AAT; EC 2.6.1.1), $\alpha$ acid phosphatase (ACP, EC 3.1.3.2), endopeptidase (ENP, EC 3.4.9.9), fluorescent esterase (EST, EC 3.1.1.-), glucosephosphate isomerase (GPI, EC 5.3.1.9), isocitrate dehydrogenase (IDH, EC 1.1.1.41), leucine aminopeptidase (LAP, EC 3.4.11.1), malate dehydrogenase ( $\mathrm{MDH}, \mathrm{EC}$ 1.1.1.37), malic enzyme (ME, EC 1.1.1.40), 6-phosphogluconate dehydrogenase (PGD, EC 1.1.1.44), phosphoglucomutase (PGM, EC 5.4.2.2), peroxidase (PRX, EC 1.11.1.7), superoxide dismutase (SOD, EC 1.15.1.1), and triose phosphate isomerase (TPI, EC 5.3.1.1) were performed on horizontal starch gels or vertical polyacrylamide gels as described previously (Manganaris and Alston 1987; Weeden and Lamb 1985, 1987). Alcohol dehydrogenase (ADH, EC 1.1.1.1) was performed on cambial scrapings as described in Hagens (1992). Using horizontal starch gels we also resolved enzyme systems not described previously in apple. These systems were alanine aminotransferase (ALAT, EC 2.6.1.2), shikimate dehydrogenase (SKDH, EC 1.1.1.25), glutamate dehydrogenase $(\mathrm{GDH}, \mathrm{EC}$ 1.4.1.2), formate dehydrogenase (FDH, EC 1.2.1.2), and aconitase (ACO, EC 4.2.1.3). Cambial scrapings were extracted for FDH analysis. Assay conditions for these new enzyme systems were as described in Wendel and Weeden (1989).

We extracted high molecular weight DNA appropriate for RFLP analysis from expanding apple leaves essentially as described in Polans et al. (1985). This DNA (10-15 $\mu$ g per sample) was restricted and subjected to Southern analysis as described in Weeden et al. (1992). The plasmids used were pHA2, containing the pea 45S RNA repeat (Jorgensen et al. 1987), plasmids kAt 3011 and jAt3012 containing the $3^{\prime}$ and $5^{\prime}$ portions of the ADH sequence from Arabidopsis thaliana (kindly provided by E. M. Meyerowitz, California Institute of Technology), and four random clones (pAP79, pAP236, pAP244, and pAP260) from an apple EcoRI genomic library in pUC13. Parental DNA was restricted with EcoRI, EcoRV, Hindlll, BamHI, BgllI, Xbal, and $D r a l$ in an initial screen to determine which enzymes generated fragments appropriate for analysis.

We extracted DNA for RAPD analysis from small amounts (ca $0.5 \mathrm{~g}$ ) of young leaf tissue by a modification of the procedure of Lassner et al. (1989) as de- scribed in Torres et al. (1993). Extracted DNA was diluted in autoclaved distilled water to a concentration of about $25 \mu \mathrm{g} /$ $\mathrm{ml}$ and subjected to amplification on a Coy Model 50 TempCycler. Each 25- $\mu$ l PCR mixture contained $2 \mu \mathrm{l}$ template DNA, 13.2 $\mu \mathrm{l} \mathrm{H}_{2} \mathrm{O}, 2.5 \mu \mathrm{l} 10 \times$ buffer, $1.25 \mu \mathrm{l}$ of $2.5 \mathrm{mM}$ of each dNTP, $0.4 \mu \mathrm{l}$ of $20-\mu \mathrm{M}$ primer, and 0.5 units Promega Taq polymerase. Cycling parameters were 40 cycles $\left(94^{\circ} \mathrm{C}, 1\right.$ $\min ; 35^{\circ} \mathrm{C}, 2 \mathrm{~min} ; 72^{\circ} \mathrm{C} ; 2 \mathrm{~min}$ ) followed by a 6 -min extension at $72^{\circ} \mathrm{C}$. Primers were synthesized at the Cornell University Biotechnology Institute or purchased from Genosys Biotechnologies, Houston, Texas. Products of the amplification reaction were separated on $2 \%$ gels ( $1 \%$ agarose and $1 \%$ NuSieve, FMC Corporation) run for $4 \mathrm{~h}$ at $100 \mathrm{~V}$ in $1 \times$ TBE buffer (Sambrook et al. 1989 ). We stained gels with ethidium bromide and photographed them on a transilluminator ( $\lambda=302 \mathrm{~nm}$ ) using Polaroid Type 55 film; segregation patterns were scored off the negatives. Scoring was always done on the basis of a "fragment present"/fragment absent" dichotomy.

\section{Powdery Mildew Resistance}

We scored resistance to powdery mildew in the field over a period of 4 years. The presence of mildew on the leaves and young branches was considered evidence of susceptibility. Plants never showing such infestations were scored as resistant.

\section{Linkage Analysis}

We divided markers into three groups: (1) those segregating as a result of heterozygosity in White Angel; (2) those segregating as a result of heterozygosity in Rome Beauty; and (3) those segregating as a result of heterozygosity in both parents. For analysis of amplified DNA fragments, we considered a parent heterozygous for a particular segregating fragment if DNA from that parent generated the fragment when used as template DNA. The expected segregation ratio for a locus heterozygous in only one parent was $1: 1$, whereas loci heterozygous in both parents were expected to display either a 3:1 ratio for dominant characters such as RAPDs or a 1:2:1 ratio for codominant allozymes and RFLPs. Goodness-of-fit between observed and expected segregation ratios was tested using chi-square analysis as performed by LINKAGE-1 (Suiter et al. 1983).

Two linkage maps were generated, one with those loci heterozygous only in White Angel and the other with loci heterozygous only in Rome Beauty. For each of the White Angel and Rome Beauty data sets, 
we performed initial joint segregation analysis on about 60 loci using LINKAGE1. Once preliminary linkage groups had been identified, we used QUIKMAP (an Excel spreadsheet operation available from N.F.W.) to map additional markers. MAPMAKER (Lander et al. 1987) was used to confirm locus order for each linkage group and to determine multipoint recombination frequencies among loci. A log-likelihood score of 3.0 and a recombination distance of no more than $20 \mathrm{cM}$ were the minimal criteria for establishing linkage between markers. The "ripple" function on MAPMAKER was employed to assess the robustness of the order of markers on a linkage group. In general, we specified an order only when no alternative marker order with an LOD within - 3.0 was available. After the maps had been assembled, we used QUIKMAP to check for the existence of significant linkages between markers in different linkage groups.

The White Angel and Rome Beauty maps were compared, and we identified corresponding linkage groups using loci heterozygous in both parents (for detailed description of this technique see Hagens 1992; Lawson DM, Hemmat M, and Weeden NE, unpublished manuscript). Only data for which the contribution of each parent was unambiguous were used for mapping loci heterozygous in both parents; hence, only the homozygous genotypes were used to map isozyme and RFLP markers. For RAPD markers, heterozygotes could not be distinguished from the homozygous 'fragment-present' phenotype, so only the homozygous recessive (fragment-absent) genotypes were used for this analysis.

\section{Results}

We identified 409 segregating markers in the population. A complete list of these markers is available upon request and is posted on the Internet Gopher (copyright 1991, University of Minnesota) under Cornell University, College of Agriculture, Geneva, Department of Horticultural Sciences, Fruit Breeding and Genetics. Thirty-four of these markers were allozyme polymorphisms, eight were RFLPs, and the remainder were amplified DNA fragments generated by arbitrary primers. Most of the markers displayed segregation ratios not significantly different from the $1: 1,1: 2: 1$, or 3:1 ratio expected based on parental phenotypes. White Angel displayed heterozygosity for 268 markers, and Rome Beauty was heterozygous for 180 markers. Of these, 39 loci were heterozygous in both parents or, in the case of RAPDs where homology could not be confirmed, behaved as such by being present in both parents and segregating in the progeny.

Segregation patterns for allozyme polymorphism for AAT, ACP, ADH, DIA, EST, GPI, IDH, LAP, MDH, ME, PGD, PGM, PRX, SOD, and TPI were defined as described previously (Hagens 1992; Manganaris 1989; Weeden and Lamb 1985). Polymorphism in ALAT, ACO, FDH, GDH, and SKDH will be described in a separate paper in which a wider sample of germplasm is analyzed and discussed. For ALAT, FDH, GDH, and SKDH only a single polymorphism could be observed, although at least one additional isozyme was present in each system. For ACO, three polymorphic regions on the gel were identified. These were labeled ACO-1, ACO-2, and ACO-3 in order from the most anodal region. In total, White Angel displayed heterozygosity at 24 isozyme loci and Rome Beauty at 14 .

The RFLP patterns generated by the probes were all multibanded, usually displaying one or more monomorphic fragments in addition to those polymorphic. For the mapping analysis we used EcoRI phenotypes for pHA2, DraI for pAP260, EcoRV for pAP236, and BamHI for pAP79 and PAP244. The ADH probes revealed polymorphism with several restriction enzymes, with HindIII exposing a polymorphism for Adh-2 heterozygous in both parents (Hagens 1992). The Adh-2 RFLP heterozygous in White Angel cosegregated with the allozyme variation, indicating that the two were synonymous.

The greatest number of heterozygous markers were identified with arbitrary primers. Sixty-four primers or primer combinations were used in the analysis (Table 1). On average, 10 well-defined fragments were generated by each primer, about half of which were polymorphic (Figure 1). Several primers (e.g., P1, P5, P10, and P21) generated relatively few products. Certain pairwise combinations of these primers (e.g., $\mathrm{P} 1$ and $\mathrm{P} 5$, and $\mathrm{P} 2$ and $\mathrm{P} 10$ ) generated novel fragments and polymorphisms not produced when either of the primers was used individually.

Although duplicate samples amplified on different days using the same primer gave very similar phenotypes, some variation was noted, particularly in the less strongly amplified products (fainter bands). Overall, we found a "misscoring" or "irreproducibility" rate of between zero and $7 \%$, depending on the fragment being analyzed (Weeden et al. 1992). These rates were determined not only by replicate
Table 1. Primers used for producing RAPDs on apple linkage map

\begin{tabular}{|c|c|}
\hline $\begin{array}{l}\text { Primer } \\
\text { designation }\end{array}$ & Sequence $\left(5^{\prime}-3^{\prime}\right)$ \\
\hline $\mathrm{Tl}$ & AGT TCG TCT G \\
\hline $\mathrm{T} 2$ & TGG TGG GTC C \\
\hline T3 & CTC GGT ACA C \\
\hline $\mathrm{T} 4$ & GTG GTT GCG A \\
\hline T5 & CTG GAC TTA C \\
\hline $\mathrm{Pl}$ & CCT GTA GTG G \\
\hline P2 & TAC CTT CCG T \\
\hline P3 & GTC CGT TGG G \\
\hline P4 & GTT AGG TCG T \\
\hline P5 & TCT CTG TCC C \\
\hline P6 & TCG CCC CAT T \\
\hline P7 & CGT GGT TCC C \\
\hline P8 & GTC CCG TTA C \\
\hline P9 & ACG CCC TAG T \\
\hline P10 & TTT CAC ATG G \\
\hline P11 & CTG TGC TGT G \\
\hline $\mathrm{P} 12$ & TGG TGG ATG TA \\
\hline P13 & GGT GAT GTC C \\
\hline $\mathrm{P} 14$ & TGC CTT CCA T \\
\hline P15 & GGG TTG CCG T \\
\hline P17 & CTA TTT TGC C \\
\hline $\mathrm{P} 21$ & CCC TGT CTC $\mathrm{T}$ \\
\hline P24 & AGC ACT GTC A \\
\hline P25 & AAT GAA GCC A \\
\hline P26 & TAC TGC TGG G \\
\hline $\mathrm{P} 27$ & ACC TCG AGC A \\
\hline P28 & TCG TAG CCA A \\
\hline P30 & CAA CTG GTA ATG \\
\hline P98 & GAA CGA CGC A \\
\hline P105 & CAG TCG CGT G \\
\hline P117 & GGG ATC GTG T \\
\hline P123 & GGG ATT CGA C \\
\hline P124 & ACT ACT GCC T \\
\hline PI26 & CTG CTA CGT C \\
\hline $\mathrm{P} 129$ & CAG TCG AAC G \\
\hline P137 & ATC TGC GAC A \\
\hline P145 & TAG CGG CTA C \\
\hline P157 & GTC ATG TCG A \\
\hline P161 & CGG ATG CCT T \\
\hline P163 & ACG CCT ACG T \\
\hline $\mathrm{S} 2$ & CGA GTT GCG C \\
\hline S5 & CCG GCT CTT G \\
\hline S12 & GCG ACG CCT A \\
\hline S15 & AAC ACA TGC C \\
\hline S16 & CGT TGG ATG C \\
\hline S18 & TTT GGC TCT G \\
\hline S19 & TAC GGC TGG C \\
\hline S20 & TGA ACC GCC G \\
\hline S21 & CCC TAC CGA C \\
\hline $\mathrm{S} 22$ & CGT CGT GGA A \\
\hline S23 & CCA CGC TAT A \\
\hline S24 & GCG GCA TTG T \\
\hline S27 & AGT GGT CGC G \\
\hline S30 & GCG TAG AGA C \\
\hline S31 & CTC GAC ACT G \\
\hline S34 & GAT AGC CGA C \\
\hline S35 & AGT CGC TCA T \\
\hline $\mathrm{S} 36$ & CTC CAA GGC C \\
\hline S39 & TCG GCC TGC T \\
\hline S40 & GAC TGC TCG G \\
\hline S42 & CCC AGA ACA C \\
\hline S44 & ATT CGG CCG G \\
\hline S45 & CAC GTC GGA G \\
\hline S49 & ACC GGG CCT A \\
\hline S50 & CCC AAA CTA G \\
\hline
\end{tabular}

RAPD analyses but also by comparison with tightly linked isozyme markers (which had been scored several times) and by detailed analysis of clustered RAPD markers. For instance, the markers P123j, P24g, T4a, P3k, P137g, and S42i all gave nearly identical segregation patterns. The few recombinants identified among these mark- 


\section{$542530 \quad 536$}

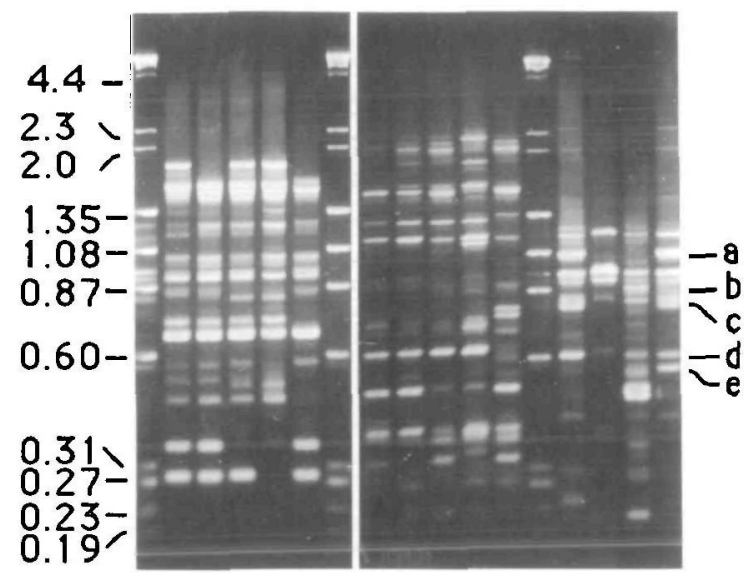

Figure 1. RAPD phenotypes obtained on parental and progeny template DNA for three primers (S42, S30, and S36). Five apple samples are shown for S42 and S30, and four are shown for S36. Lanes containing an HaelII cut $\phi \times 174 /$ Hindlll cut $\lambda$ combination size marker separate the sets. The sequence of samples within each set is (from left) three individuals from the $F$, population, Rome Beauty, and White Angel. The White Angel phenotype is not shown for S36; however, the positions of the five S36 RAPDs are marked to the right of the figure by their respective letter designations. The sizes of the marker fragments (in kbp) are given on the left of the figure.

ers did not assort themselves into a linear sequence, and the majority thus became "double recombinants" within the cluster, suggesting that these data are actually errors in amplification/scoring. We felt the most reliable way to present the linkage relationship among such loci was to disregard (i.e., treat as missing data) the results generating double recombinants within such clusters. This option caused such clusters to condense and shortened the linkage map around these regions. However, new linkages were not formed, nor were significant alterations in marker sequence produced by this operation.

\section{Linkage Analysis}

The White Angel map possessed 253 markers arranged on 24 linkage groups, covering $950 \mathrm{cM}$ (Figure 2). Five markers, heterozygous only in White Angel, could not be placed on the map. Results for Rome Beauty were similat except that considerably fewer (156) markers were mapped and 14 markers assorted independently (Figure 2). In addition, 10 RAPDs that appeared to be heterozygous in both parents could not be located on the linkage map. The map for White Angel was chosen as the standard map for additional comparisons and analysis because it included more markers. All linkage groups in both parents were found to be well defined. Markers on one linkage group did not display significant linkage (LOD $>3.0$, recombination fraction $<25 \mathrm{cM}$ ) with any marker on a different linkage group. Some weak linkages $(>25 \mathrm{cM}$ ) between markers on different linkage groups were identified. However, the large number of markers being compared made it likely that such linkages would be identified in a group of randomly assorting markers, and we disregarded these correlations when assembling our groups.

Homologous counterparts to 15 of the White Angel linkage groups were identified on the Rome Beauty map using markers heterozygous in both parents (Figure $2)$. For six linkage groups $(3,5,6,7,9$, and 10) the homology was confirmed by two or more markers, permitting the homologous linkage groups to be placed in the same orientation relative to each other. Rome Beauty counterparts to the relatively long White Angel linkage groups 1, 2, and 8 could not be identified. Conversely, three long $(>30 \mathrm{cM})$ linkage groups of Rome Beauty were not paired with White Angel linkage groups through loci heterozygous in both parents. However, previous studies on linkage relationships among isozyme loci in apple (Manganaris 1989; Weeden and Lamb 1987) suggest that the Rome Beauty linkage group containing $P g m-1$ and Tpi-c2 was not homologous to linkage groups 1 or 2 of White Angel. This linkage group is particularly important for breeders (see Discussion), and we have defined our linkage group 8 using the Rome Beauty group rather than that from White Angel. At present, we have no direct evidence of homology between the White Angel and Rome Beauty linkage group 8 . The two are paired because both are of such length ( $>60 \mathrm{cM})$ that it would be difficult to incorporate either into one of the other paired linkage groups identified.

\section{Distribution of RAPDs}

Approximately $80 \%$ of the RAPDs on a particular White Angel linkage group did not appear to have counterparts on the corresponding Rome Beauty linkage group. However, $6 \%$ of the RAPDs appeared to be produced by both parents, and at least another $5 \%$ of the amplified fragments showed similar intensity and size in both parents but did not segregate in the progeny. In addition, a primer would occasionally produce an RAPD in a similar location on both maps, although the size of the fragment would differ. For instance, primer P4 produced an 850-bp RAPD on the White Angel linkage group 14 and a fragment of size 930 bp at a corresponding position on the Rome Beauty map. A similar correlation occurred for primers S34 and P123 on linkage group 16. In addition, several cases were noted where an RAPD heterozygous in both parents showed tight linkage with another RAPD generated by the same primer (e.g., P98a, P98b, and P98i on linkage group $9 ; \mathrm{S} 45 \mathrm{c}$ and $\mathrm{S} 45 \mathrm{f}$ on group 3; P27a and P27e on group 6; and P27c and P27d on group 14).

In most cases the separate DNA fragments generated by a single primer assorted independently; however, in several cases such fragments demonstrated linkage or even tight clustering. For instance, the 820 - and 550 -bp fragments generated by S20 both mapped on White Angel chromosome 12, although a significant distance apart. A similar situation was observed on linkage group 8 for the 1030 - and 350 -bp fragments produced by primer $\mathrm{S} 15$, and for $\mathrm{P} 117 \mathrm{f}$ and $\mathrm{j}$ on Rome Beauty group 10 . The 880- and 420-bp fragments of S16 both mapped at the end of White Angel linkage group 6. Several such clusters also were evident on the Rome Beauty map: P98d and f, P117d and I, P123d and k, and S49b and p.

The most conspicuous clusters on the map contained RAPD markers generated by different primers. One of these clusters was found on both the White Angel and Rome Beauty group 16. In White Angel this cluster included 11 RAPD markers within $10 \mathrm{cM}$, whereas in Rome Beauty six markers clustered within this distance. Smaller clusters were found on nearly all linkage groups.

\section{Comparison of Male and Female Recombination Frequencies}

Loci heterozygous in both parents were used to identify homologous linkage 

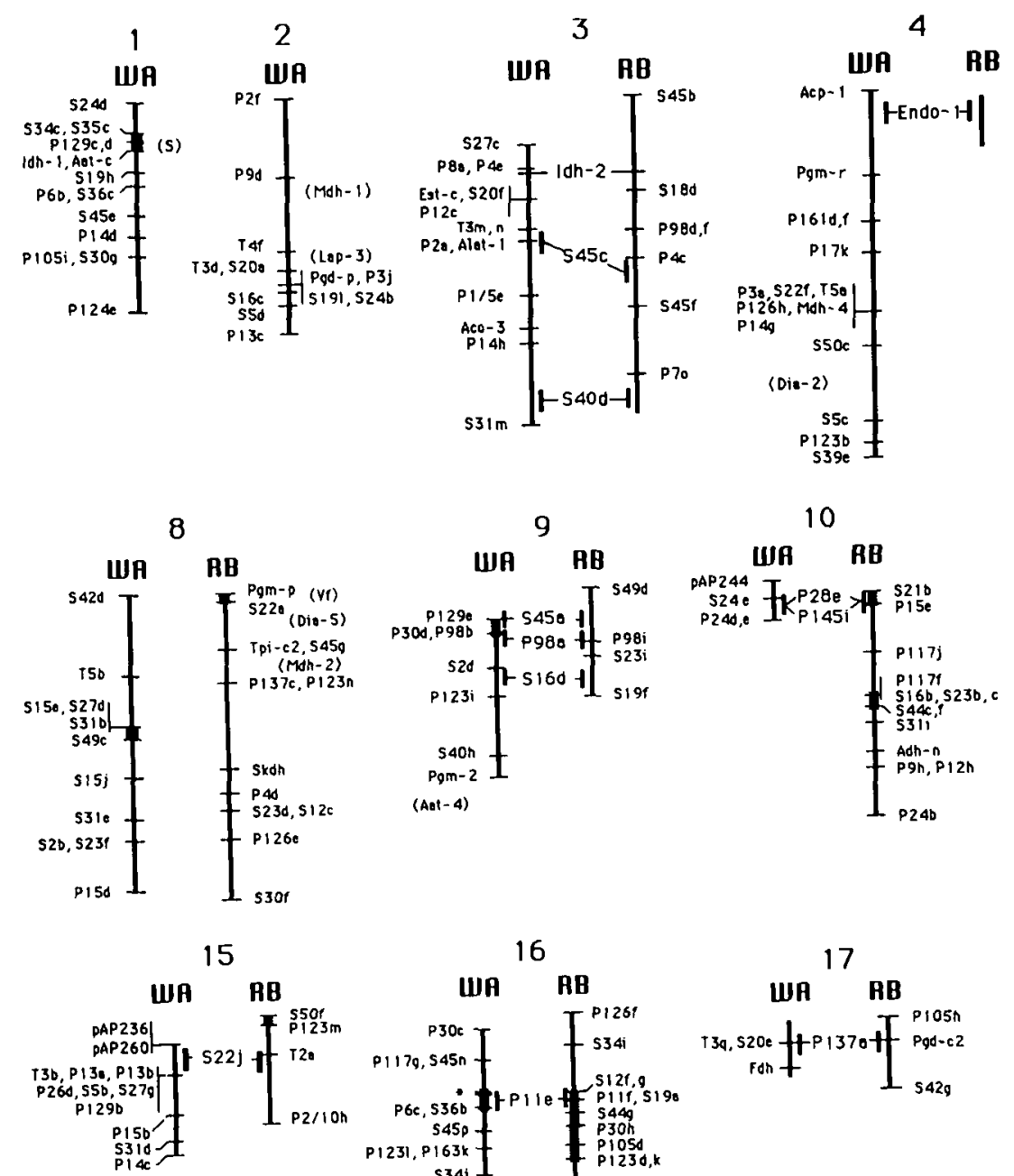

16

แผค $\mathrm{AB}$

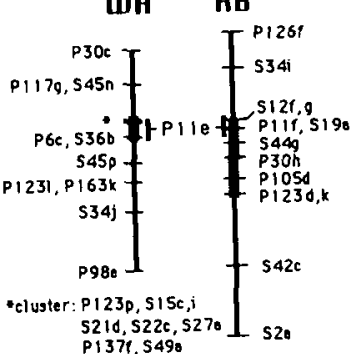

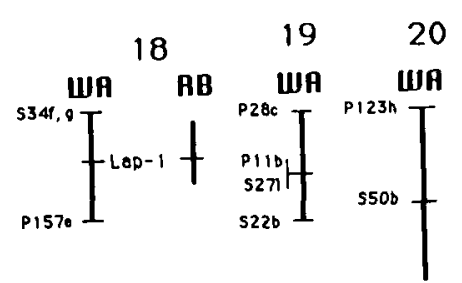
$5210,5226,5270$
520

\section{แIA $\mathrm{AB}$}

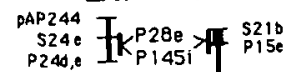

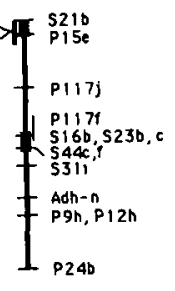

แค $\mathrm{RB}$

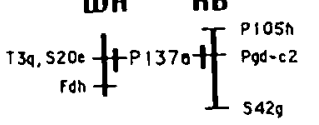

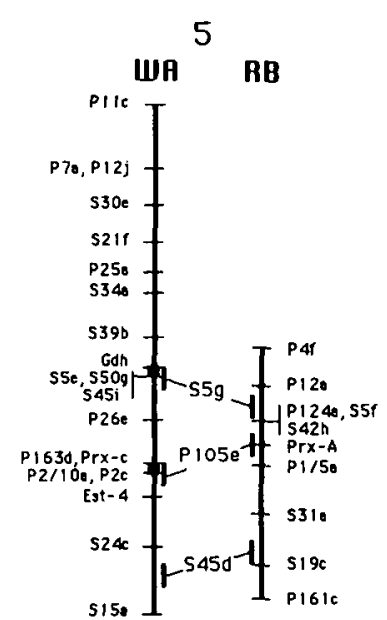
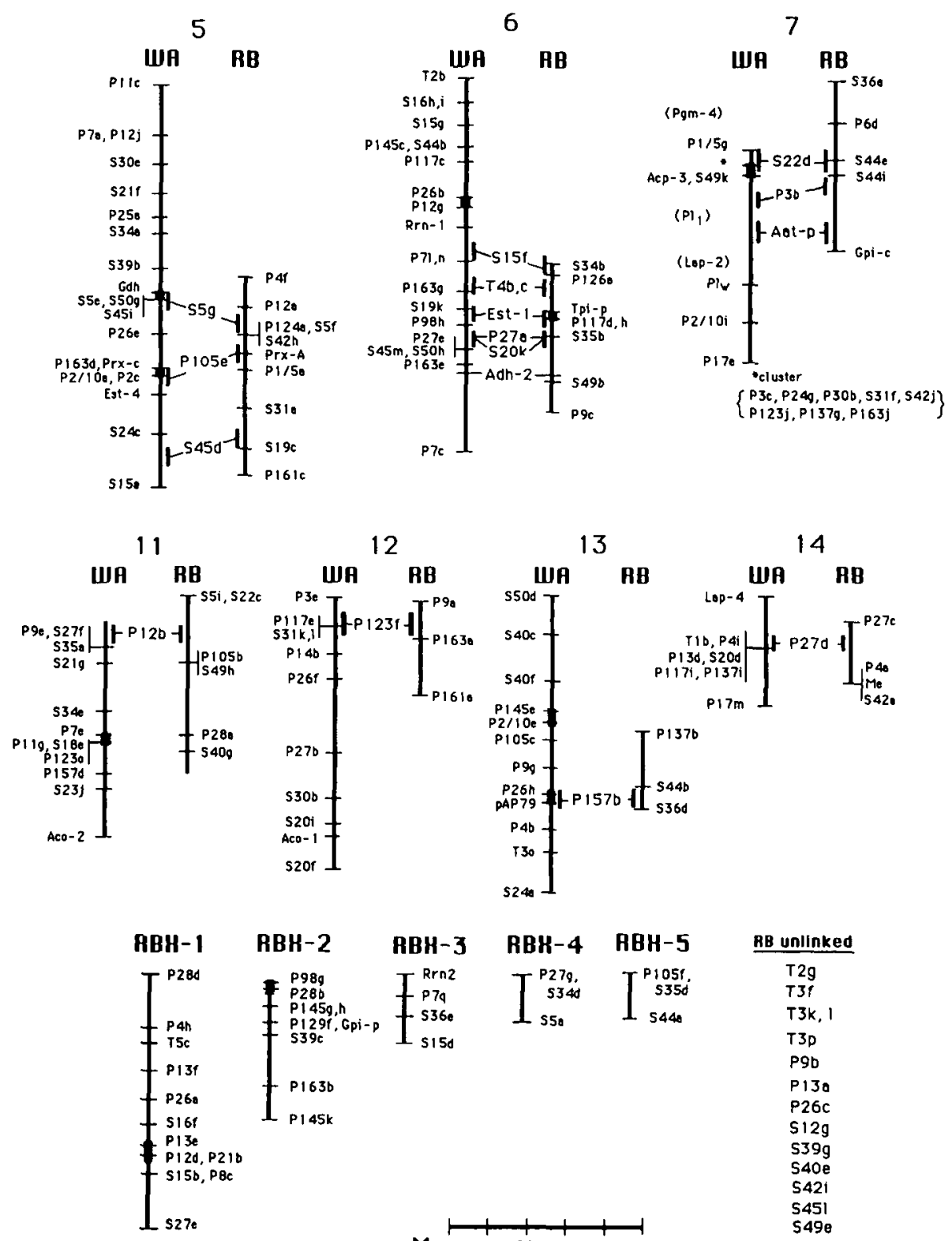

RBH-4 HВH-5

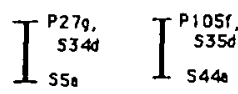

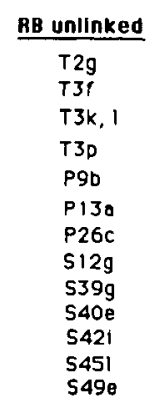

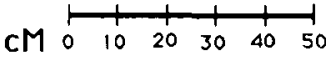

Figure 2. Linkage maps for White Angel (WA) and Rome Beauty (RB). Markers heterozygous in both parents are placed between the respective WA and RB linkage groups on which they mapped. RBX identifies five Rome Beauty linkage groups that could not be associated with White Angel groups on the standard map. The approximate locations of markers or genes not segregating in the test population are noted by
gene symbols in parentheses. The wider, checkered sections within a linkage group indicate regions where the LOD for marker sequence is -2.0 to -3.0 . In all other regions the sequence LOD was at least -3.0 . 
groups. Mapping of more than one such locus on a linkage group permits the direct comparison of recombination frequencies in the male and female parents for the segment of the map between the two loci. Such comparisons can be made for loci on linkage groups $3,5,6,7$, and 9 . On linkage group 5, Rome Beauty exhibits higher recombination rates between markers; however, White Angel showed higher levels of recombination on group 6 (Table 2). On groups 3,7 , and 9 the average recombination frequency is nearly equal for the two parents, although the placement of P105e on each of the group 5 maps suggests that recombination frequencies for specific segments of the maps may differ between the parents.

Unfortunately, when a locus is heterozygous for the same alleles in both parents, the contribution of each parent is ambiguous for certain phenotypes (e.g., heterozygotes for codominant alleles and the dominant phenotype for RAPDs and other dominant/recessive markers). Hence, only half or one-fourth of the population gave data useful for determining the position of markers heterozygous in both parents. Consequently, the location of these markers is much less precise than the locations of the markers heterozygous in only one parent. In Figure 2 the positions of most of the markers heterozygous in both parents are represented by a bar parallel to a region of the respective linkage maps, reflecting the greater uncertainty associated with this position. The high uncertainty of the linkage estimates given in Table 2 also reflects this limitation. The exceptions to this convention-Idh-2 on group 3, Adh-2 on group 6, and Lap-1 on group 18-gave segregation phenotypes in which the allelic contributions of the parents were unambiguous, and their positions could be determined with the standard precision.

\section{Discussion}

Extensive linkage maps for two apple clones, one a common commercial variety and the other a crabapple with possible $M$. seiboldii heritage, were generated using allozyme and DNA polymorphisms. These maps were generated in an $F_{1}$ population produced by crossing the two varieties and taking advantage of the high level of heterozygosity often present in long-lived, self incompatible species. This high heterozygosity in apple has been documented by several investigators (Chevreau et al. 1985; Manganaris 1989; Weeden and Lamb 1987), and many loci can be expected to segregate in the immediate progeny of any cross. In the present cross, White Angel exhibited about $50 \%$ more heterozygosity than Rome Beauty, presumably reflective of its more diverse parentage.

The development of the maps was greatly facilitated by the use of short oligonucleotide primers to generate discrete amplified segments of DNA as described in Williams et al. (1990). These markers were found to be particularly suitable for our approach to genetic analysis in apple. An average of six polymorphisms per primer was obtained in this study, and comparable levels have been observed in other populations (Hemmat $M$, unpublished data). With such high levels of polymorphisms generated by single primers, we found little need to use primers in pairs. The small gain in resolved RAPDs when we combined certain primers (e.g., Pl and P5) was not cost-effective.

The dominant nature of RAPD markers did not represent a significant disadvantage in our analysis. At least for the case in which only one parent is heterozygous, a dominant/recessive allelic system will display the same 1:1 segregation ratio as any other polymorphic locus. Hence, the dominance problem that hinders the application of RAPD markers in mapping many annual crops, such as maize and soybean, appears to be much less of a problem in highly heterozygous species. Only when an RAPD fragment is heterozygous in both parents does the fragmentpresent phenotype represent an ambiguous genotype in the progeny. In this case the fragment-absent phenotype is still useful for mapping the polymorphism, but as it occurs only in one-fourth of the progeny the amount of data available for linkage tests is greatly reduced. Such RAPDs are particularly useful for identifying homologous linkage groups between the two parents, and we attempted to map all that we encountered. We were successful only about $60 \%$ of the time despite being able to map over $90 \%$ of the polymorphisms heterozygous in only one parent.

The utility of RAPD markers also is believed to be limited by the difficulty in identifying homologous markers in different crosses. Our results suggest that only $10 \%-20 \%$ of the amplified fragments were common to both parents. However, White Angel and Rome Beauty represent widely divergent apple germplasm. Preliminary studies in our laboratory on a series of commercial apple varieties indicate that these share a much higher proportion of
Table 2. Comparison of map distances between syntenic markers mapped on both the Rome Beauty and White Angel linkage groups

\begin{tabular}{|c|c|c|c|c|}
\hline \multirow[b]{2}{*}{$\begin{array}{l}\text { Linkage } \\
\text { group }\end{array}$} & \multirow{2}{*}{\multicolumn{2}{|c|}{ Markers }} & \multicolumn{2}{|c|}{ Calculated distance } \\
\hline & & & $\begin{array}{l}\text { Rome } \\
\text { Beauty }\end{array}$ & $\begin{array}{l}\text { White } \\
\text { Angel }\end{array}$ \\
\hline 3 & Idh-2 & : S40d & $39 \pm 12$ & $39 \pm 12$ \\
\hline 5 & S5g & : S45d & $34 \pm 16$ & $26 \pm 15$ \\
\hline 6 & $\mathrm{~S} 15 \mathrm{f}$ & : Adh-2 & $38 \pm 14$ & $42 \pm 17$ \\
\hline 7 & $\mathrm{~S} 22 \mathrm{~d}$ & : Aat-p & $20 \pm 20$ & $22 \pm 10$ \\
\hline 9 & $\mathrm{~S} 45 \mathrm{a}$ & : S16d & $17 \pm 11$ & $18 \pm 14$ \\
\hline
\end{tabular}

amplified fragments. The recent use of RAPDs to fingerprint apple varieties by Koller et al. (1993) also indicates that a majority of the amplified products are conserved among many commercial varieties. More important, apple breeders often use a limited number of parents repeatedly in their breeding programs. For instance, the variety Golden Delicious has often been used as a parent because it consistently produces progeny of commercial quality. RAPD markers identified in such important varieties are likely to be useful in many breeding programs. Thus, the limitations associated with the use of RAPDs in the genetic analysis of annual crops or wild populations are at least partially mitigated by characteristics and breeding techniques peculiar to longer lived crops.

In most cases, the White Angel and Rome Beauty maps were consistent with previous findings (Manganaris 1989; Weeden and Lamb 1987). Aat-c was tightly linked to Idh-l on linkage group 1 ; Acp-1, Enp-I, and the modifier of PGM phenotype, $P$ gm$r$, mapped near each other on linkage group 4 ; and powdery mildew resistance, $P l_{w}$, showed linkage to $A c p-3$ and Aat-p as was reported by Manganaris (1989), although a more tightly linked isozyme marker, Lap-2 could not be resolved in our cross. Manganaris (1989) found $P G D-3$ to be linked to $I d h-1$. Our locus Pgd-c2, positioned on the short linkage group 17, may be the same as $P G D-3$. However, markers on the White Angel group 17 assorted independently of markers on linkage group 1. Manganaris also found linkage between Lap-1 and $P g m$-2. Our data could not confirm this linkage, but the intermediate isozyme locus, Aat -4 (=GOT-4) was not segregating in our population. If the two loci are on the same linkage group, group 18 can be assigned to the lower end of group 9 . We were not able to confirm the $P g m-2-A d h-2$ linkage reported by Manganaris (1989). In our cross, Adh-2 cosegregated with markers on linkage group 6, whereas $\mathrm{Pgm}$-2 displayed linkage with markers on group 9. 
These inconsistencies may reflect chromosomal rearrangement known to be present in the apple germplasm (Zhu M and Gardiner $S$, personal communication).

Several markers not segregating in either parent could be located on the map based on previously determined linkages. These are given in parentheses at their respective positions in Figure 2. They include the self incompatibility locus, $S$, on linkage group 1 (Manganaris and Alston 1987); Lap-3 and $M d h-l$ on group 2 (Manganaris 1989); Dia-2 on group 4 (Weeden and Lamb 1987); Pgm-4, $P l_{1}$, and Lap-2 on group 7 (Manganaris 1989); and $V_{f}$ Dia-5, and $M d h-2$ on group 8 (Manganaris 1989 ; Weeden and Lamb 1987). The loci $S, V_{h}$ $P l_{w}$, and $P I_{1}$ are particularly important for apple breeders as they govern self incompatibility, scrab resistance, and powdery mildew resistance, and it is crucial to have their locations on the map well documented.

The combination of the two maps using markers heterozygous in both parents represents a specialized application of genetic principles that is appropriate when generating maps in such outcrossing species. Codominant loci were particularly useful in this application because, theoretically, half of the progeny (those homozygous for either allele) give information useful for mapping. Hagens (1992) used isozymes and RFLPs to convincingly demonstrate the homology between linkage groups 6 of White Angel and Rome Beauty, and the isozyme loci Id $h$-2 and Aat-p clearly established linkage groups 3 and 7 , respectively, in both parents. In contrast, for dominant/recessive markers, only a quarter of the progeny (those homozgyous for recessive allele) give useful information for identifying homologous chromosomes. Several of the RAPDs heterozygous in both parents could not identify homologous groups because the amount of informative data was too small, and homologies established on the basis of a single RAPD marker (e.g., groups 11-17) must be accepted with a degree of caution.

On linkage groups where more than one locus heterozygous in both parents were mapped, a comparison of the recombination frequencies producing male and female gametes could be made. Although several studies have indicated a lower level of recombination rates in male versus female gametogenesis (de Vicente and Tanksley 1991; Rick 1969, 1972; Robertson 1984), our results indicate approximately equal recombination frequencies for the two parents. Our results could not account for possible effects of the different genetic background in the two parents, and the less precise mapping of the doubly heterozygous loci used for the comparison also may have obscured a small consistent difference in recombination frequency. Thus, our conclusion that the data do not suggest a lower recombination level in White Angel must be considered preliminary. A more complete survey of the apple genome using reciprocal crosses is in progress.

A particular concern of many researchers working with RAPD markers is the reliability and reproducibility of this technique. We observed an error frequency of about $5 \%$ in scoring RAPD markers in pea (Weeden et al. 1992) and anticipated that our RAPD data in apple also would show this level of inconsistency. We attempted to eliminate or correct for such errors by using a DNA extraction procedure that gives small amounts of very high quality DNA, by scoring only very clear polymorphisms, and by anchoring most linkage groups with allozyme or restriction fragment length polymorphisms. These measures appear to have been successful because internal controls and data analysis estimated only a $2 \%$ error in our RAPD data (Weeden et al. 1992). Most of the clear RAPDs could be easily and confidently mapped with approximately the number of double crossovers expected from the distances involved. Concordance of segregation data in clusters of nonrelated RAPD markers also demonstrated the general accuracy of the data. In cases where recombination was observed between an RAPD fragment and another marker, the flanking markers on each side generally verified the recombination event. However, in certain cases there appeared to be a surplus of double recombination events. Treating such data as missing data resolved inconsistencies in marker sequence and shortened the linkage map in several regions. To avoid identifying false linkages by such changes, we only reported linkages conforming to the strict conditions of an LOD score of at least 3.0 and a recombination distance of no more than $20 \mathrm{cM}$. Thus, in no case did the changes identify new linkages or significantly alter the sequence of markers along a linkage group. However, this treatment did shorten the total length of the apple linkage map by $50 \mathrm{cM}-100 \mathrm{cM}$.

We believe that the approach used to construct the linkage maps for apple is appropriate for a number of woody perennial crops for which relatively few parental lines are used in breeding programs. RAPD markers permit an extensive map to be generated quickly and relatively inexpensively, and such maps can be used to investigate the genetic basis of important morphological or physiological variation. Tags for commercially important genes such as those conferring disease resistance can be quickly identified, and because relatively few parental sources are used, these tags can be widely applied in . breeding programs. We expect the use of the pseudotestcross and the double pseudotestcross design to greatly facilitate mapping in highly heterozygous plant species.

\section{References}

Beach SA, Booth NO, and Taylor OM, 1905. The apples of New York, 2 vols. NY Agric Exp Stn Rep 1903

Carlson JE, Tulsieram LK, Glaubitz JC, Luk VWK, Kauffeldt $C$, and Rutledge $R, 1991$. Segregation of random amplified DNA markers in $F_{1}$ progeny of conifers. Theor Appl Genet 83:194-200.

Cheliak WM, Morgan K, Dancik BP, Strobec KC, and Yeh FC, 1984. Segregation of allozymes in megagametophytes of viable seed from a natural population of jack pine, Pinus banksiana Lamb. Theor Appl Genet 69:145-151.

Chevreau E and Laurens F, 1987. The pattern of inheritance in apple (Malus $\times$ domestica Borkh.): further results from leaf isozyme analysis. Theor Appl Genet 75:90-95.

Chevreau E, Lespinasse $Y$, and Gallet $M, 1985$. Inher itance of pollen enzymes and polyploid origin of apple Malus $\times$ domestica Borkh.). Theor Appl Genet 71:268277.

de Vicente MC and Tanksley SD, 1991. Genome-wide reduction in recombination of backcross progeny derived from male versus female gametes in an interspecific cross of tomato. Theor Appl Genet 83:173-178.

Eckert RT, Joly R, and Neale DB, 1981. Genetics of isozyme variants and linkage relationships among allozyme loci in 35 eastern white pine clones. Can J For Res 11:573-579.

El-Kassaby YA, Sziklai O, and Yeh FC, 1982. Linkage relationships among 19 polymorphic allozyme loci in coastal Douglas-fir (Pseudotsuga menziesii var. 'menziesii'). Can J Genet Cytol 124:101-108.

Grattapaglia D, Chaparro J, Wilcox P, McCord S, Wer ner $D$, Amerson $H$, McKeand S, Bridgwater F, Whetten R, O'Malley D, and Sederoft R, 1992. Mapping in woody plants with RAPD markers: application to breeding in forestry and horticulture. In: Applications of RAPD technology to plant breeding. Madison, Wisconsin: Plant Science Society of America; 37-40.

Guries RP, Friedman ST, and Ledig FT, 1978. A megagametophyte analysis of genetic linkage in pitch pine (Pinus rigida Mill.). Heredity 40:309-314.

Hagens DM, 1992. Genetic studies in Malus: integration of isozymes, DNA markers and morphological traits (MS thesis). Ithaca, New York: Cornell University.

Hamrick JL and Godt MJW, 1990. Allozyme diversity in plant species. In: Plant population genetics, breed ing and genetic resources (Brown AHD, Clegg MT, Kahler $A L$, and Weir BS, eds). Sunderland, Massachusetts: Sinauer; 43-63.

Jefferson RM, 1970. History, progeny and locations of crabapples of documented authentic origin. National Arboretum Contribution no. 2. Beltsville, Maryland: ARS/USDA 
Jorgensen RA, Cuellar CE, Thompson WF, and Kavanagh TA, 1987. Structure and variation in ribosomal RNA genes in pea. Plant Mol Biol 8:3-12.

Koller B, Lehmann A, McDermott JM, and Gessler C, 1993. Identification of apple cultivars using RAPD markers. Theor Appl Genet 85:901-904.

Lander ES, Green P, Abrahamson I, Barlow A, Daly MJ Lincoln SL, and Newbers L, 1987. MAPMAKER: an interactive computer package for constructing primary genetic linkage maps of experimental populations. Genomics 1:182-195.

Lassner MW, Peterson P, and Yoder JI, 1989. Simultaneous amplification of multiple DNA fragments by polymerase chain reaction in the analysis of transgenic plants and their progeny. Plant Mol Biol Rptr 7:116128.

Manganaris AG, 1989. lsoenzymes as genetic markers in apple breeding (PhD dissertation). London: University of London.

Manganaris AG and Alston FH, 1987. Inheritance and linkage relationships of glutamate oxaloacetate transaminase isoenzymes in apple: 1 . The gene Got-1, a marker for the $S$ incompatibility locus. Theor Appl Genet 74:154-161.

Manganaris AG and Alston FH, 1988a. The acid phosphatase gene $A C P-I$ and its linkage with the endopeptidase gene ENP-I and the pale green lethal gene $l$ in apple. Acta Hort 224:177-184.

Manganaris AG and Alston FH, 1988b. Inheritance and linkage relationships of glutamate oxaloacetate trans aminase isoenzymes in apple: 2 . The genes Got-2 and Got-4. Theor Appl Genet 76:449-454.
Manganaris AG and Alston FH, 1992. Genetics of leucine aminopeptidase in apple. Theor Appl Genet 83 345-352.

Neale DB and Williarns CG, 1991. Restriction fragment length polymorphism mapping in conifers and applications to forest genetics and tree improvement. Can J For Res 21:545-554.

O'Malley DM, Allendorf FM, and Blake GM, 1979. Inheritance of isozyme variation and heterozygosity in Pinus ponderosa. Biochem Genet 17:233-250.

Polans NO, Weeden NF, and Thompson WF, 1985. In heritance, organization, and mapping of $r b c S$ and $c a b$ multigene families in pea. Proc Natl Acad Sci USA 82 5083-5087.

Rick CM, 1969. Controlled introgression of chromo some of Solanum pennellii into Lycopersicon esculen tum: segregation and recombination. Genetics 62:753768.

Rick CM, 1972. Further studies on segregation and re combination in backcross derivatives of a tomato species hybrid. Biol Zentralbl 91:209-220.

Robertson DS, 1984. Different frequency in the recov ery of crossover products from male and female gametes of plants hypoploid for B-A translocations in maize. Genetics 107:117-134.

Sambrook J, Fritsch EF, and Maniatis T, 1989. Molec ular cloning: a laboratory manual, 2 nd ed. Cold Spring Harbor, New York: Cold Spring Harbor Laboratory Press.

Simon CJ and Weeden NF, 1991. Elucidation of crab- apple lineage by direct examination of rDNA sequences. Malus 5:4-6.

Suiter KA, Wendel JF, and Case JS, 1983. LINKAGE-1: a PASCAL computer program for the detection and analysis of genetic linkage. $J$ Hered 74:203-204.

Torres AM, Weeden NF, and Martin A, 1993. Linkage between isozyme, RFLP and RAPD markers in Vicio faba. Theor Appl Genet 85:937-945.

Tulsieram LK, Glaubitz JC, Kiss G, and Carlson JE, 1992. Single tree genetic linkage mapping in conifers using haploid DNA from megagametophytes. Bio/ Technology 10:686-690.

Weeden NF and Lamb RC, 1985. Identification of apple cultivars by isozyme phenotypes. J Am Soc Hort Sci 110:509-515

Weeden NF and Lamb RC, 1987. Genetics and linkage analysis of 19 isozyme loci in apple. J Am Soc Hort Sci 112:865-872.

Weeden NF, Muehlbauer FJ, and Ladizinsky G, 1992. Extensive conservation of linkage relationships between pea and lentil genetic maps. J Hered 83:123129.

Wendel JF and Weeden NF, 1989. Visualization and interpretation of plant isozymes. In: lsozymes in plant biology (Soltis DE and Soltis PS, eds). Portland, Oregon: Dioscorides Press; 5-45.

Williams J, Kubelik AR, Livak DJ, Rafalski JA, and Tingey SV, 1990. DNA polymorphisms amplified by arbitrary primers are useful as genetic markers. Nucleic Acids Res 18:6531-6535. 